\title{
Correction to: Frustrated Lewis Pairs Based on Transition Metals
}

\author{
Nereida Hidalgo, Macarena G. Alférez, and Jesús Campos
}

\section{Correction to:}

\section{Chapter 9 in: J. Chris Slootweg and A. R. Jupp (eds.),} Frustrated Lewis Pairs, Molecular Catalysis 2, https://doi.org/10.1007/978-3-030-58888-5_9

The original version of the book was revised: Scheme 9.25 in chapter 9 has been updated as shown below. The chapter and book have been updated with this change.
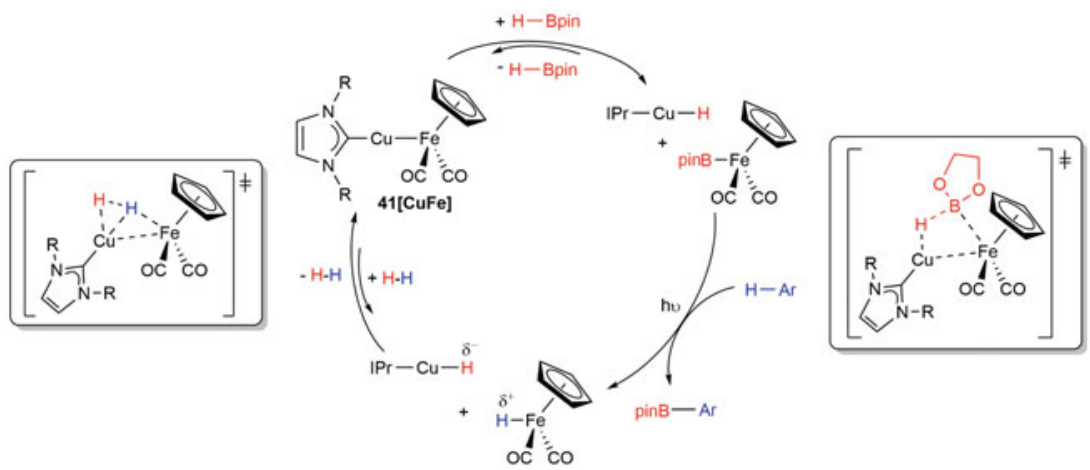

Scheme 9.25 Proposed catalytic cycle for $\mathrm{C}-\mathrm{H}$ borylation mediated by polar heterobimetallic compound $41[\mathrm{CuFe}]$ highlighting key cooperative transition states 